\title{
Phase I Study of Definitive Radio-chemotherapy with Cisplatin, 5-Fluorouracil and Cetuximab for Unresectable Locally Advanced Esophageal Cancer
}

\author{
DIRK RADES ${ }^{1}$, ANNETT MADERER ${ }^{2}$, ANNIKA PANZNER ${ }^{1}$, PETER HUNOLD ${ }^{3}$, \\ VISVAKANTH SIVANATHAN $^{2}$, HEINZ SCHMIDBERGER ${ }^{4}$ and MARKUS H. MOEHLER ${ }^{2}$ \\ Departments of Radiation ${ }^{1}$ Oncology and ${ }^{3}$ Radiology, University of Lübeck, Lübeck, Germany; \\ Departments of ${ }^{2}$ Gastroenterology and ${ }^{4}$ Radiation Oncology, Johannes Gutenberg University, Mainz, Germany
}

\begin{abstract}
Background/Aim: Prognoses of patients receiving radio-chemotherapy with 5-fluorouracil (5-FU) and cisplatin for unresectable esophageal cancer may be improved with the addition of cetuximab. This phase I study aimed to define the maximum tolerated dose of 5-FU when combined with cisplatin, cetuximab and radiotherapy. Patients and Methods: Treatment included 59.4 Gy of radiotherapy concurrently with two courses of cisplatin $\left(20 \mathrm{mg} / \mathrm{m}^{2}, \mathrm{dl}-4\right)$ and $5-F U$ (dose level 0: $500 \mathrm{mg} / \mathrm{m}^{2}$, dose level 1: $750 \mathrm{mg} / \mathrm{m}^{2}, \mathrm{dl}-4$; dose level 2: $\left.1,000 \mathrm{mg} / \mathrm{m}^{2}, \mathrm{d1}-4\right)$, followed by two courses of chemotherapy. Cetuximab was given for 14 weeks $\left(400 \mathrm{mg} / \mathrm{m}^{2}\right.$ loading dose followed by $250 \mathrm{mg} / \mathrm{m}^{2}$ weekly). Results: At dose level $1(n=3)$ and $2(n=3)$, no patient experienced a dose-limiting toxicity. Minor treatment modifications were due to organization or request by physicians/patients. At dose level 2, only five grade 3 adverse events occurred. Conclusion: Dose level 2 appears safe and is used in a subsequent randomized phase II study.
\end{abstract}

Esophageal cancer is considered a highly aggressive malignancy generally associated with a poor survival prognosis. It represents the sixth most common cause of cancer-related deaths worldwide $(1,2)$. Due to advances in surgical techniques and multi-modality treatments, the prognosis of non-metastatic esophageal cancer has slowly improved over the past decades $(3,4)$. However, the overall 5-year survival probability is still poor and needs to be considerably improved (5). This is

This article is freely accessible online.

Correspondence to: Dirk Rades, MD, Department of Radiation Oncology, University of Lübeck, Lübeck, Ratzeburger Allee 160, D-23562 Lübeck, Germany. Tel: +49 45150045401, Fax: +49 45150045404, e-mail: Rades.Dirk@gmx.net

Key Words: Locally advanced esophageal cancer, definitive radiochemotherapy, cetuximab, phase I study, dose-limiting toxicities. particularly true for patients with locally advanced unresectable disease. Many of these patients receive definitive radiochemotherapy, mostly consisting of cisplatin and 5-fluorouracil (5-FU) (6-9). It is questionable whether intensification of the systemic treatment could improve the outcome of these patients.

Cetuximab, a monoclonal epidermal growth factor receptor (EGFR) antibody, has shown considerable efficacy when combined with radiotherapy in patients with head-andneck cancer $(10,11)$. It appears likely that the addition of cetuximab to radio-chemotherapy could improve the prognosis also of patients with locally advanced esophageal cancer. However, the optimal regimen of radio-chemotherapy and cetuximab still needs to be defined. The aim of this study was to identify the maximum tolerated dose of 5-FU in combination with radiotherapy, cisplatin and cetuximab.

\section{Materials and Methods}

Patients were included in this phase I study between 2008 and 2009 after giving their written informed consent and received definitive radio-chemotherapy for unresectable locally advanced esophageal cancer. The study protocol was approved by the ethics committee of the University of Lübeck. Irradiation was performed as threedimensional conformal radiotherapy with 6-18 MV photons following computed tomography-based treatment planning. Initially, $50.4 \mathrm{~Gy}$ were administered to the primary tumor and the regional lymph nodes with daily doses of $1.8 \mathrm{~Gy}$ given on five consecutive days per week, followed by a boost dose of 9 Gy with the same fractionation to the primary tumor and involved lymph nodes. Concurrently with radiotherapy, two courses of cisplatin (intravenous bolus of $20 \mathrm{mg} / \mathrm{m}^{2}$ on days 1-4) and 5-FU (different dose levels as continuous infusion over 96 hours on days 1-4) were administered, followed by another two courses of chemotherapy without concurrent irradiation. In addition to this radio-chemotherapy program, weekly cetuximab was given for a total of 14 weeks. A loading dose of $400 \mathrm{mg} / \mathrm{m}^{2}$ administered one week prior to radiotherapy was followed by 13 weekly doses of $250 \mathrm{mg} / \mathrm{m}^{2}$. The flow chart of the study design is shown in Figure 1.

Dose-limiting toxicities (DLTs), which were defined as any grade $>3$ toxicity, dose reduction of chemotherapy or radiotherapy by 


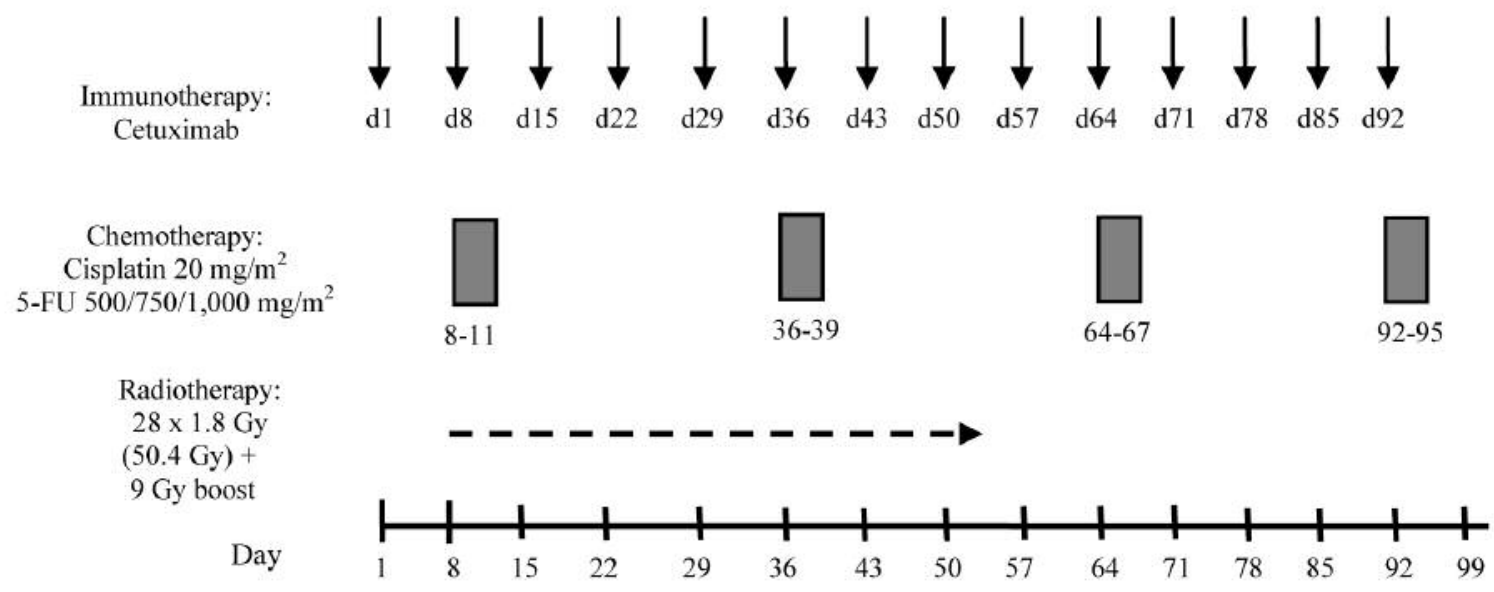

Figure 1. Flow chart of the study design.

$>30 \%$ or interruption of the treatment for longer than 14 days, were assessed from the start of radiotherapy until 10 days following its scheduled completion (Table I). Skin toxicity and allergic or hypersensitivity reactions related to cetuximab were not regarded as DLTs. A full safety evaluation was performed for all patients treated at dose level 1, before any patient could be enrolled at dose level 2 .

Three dose levels were available for the administration of 5-FU, namely dose level $1\left(750 \mathrm{mg} / \mathrm{m}^{2} /\right.$ day on days $\left.1-4\right)$, dose level 2 $\left(1,000 \mathrm{mg} / \mathrm{m}^{2} /\right.$ day on days $\left.1-4\right)$ and dose level $0\left(500 \mathrm{mg} / \mathrm{m}^{2} /\right.$ day on days $1-4)$. The traditional $3+3$ design was applied to specify the safe dose of 5-FU for a subsequent study. Initially, three patients were treated at dose level 1 . If no patient experienced a DLT, the next three patients would have been treated at dose level 2. In case of one DLT at dose level 1, another three patients would have been treated at this dose level. If one of six patients at dose level 1 experienced a DLT, the next three patients would have been treated at dose level 2 . No dose escalation was performed beyond level 2. If two of three or two of six patients, respectively, at dose level 1 experienced a DLT, the next three patients had to be treated at dose level 0 . If two of three or two of six patients, respectively, at dose level 0 experienced a DLT, the combination of radio-chemotherapy with cisplatin and 5-FU plus cetuximab had to be considered not feasible.

\section{Results}

In the three patients treated at dose level 1 (Table II), a delay of administration of cetuximab of more than 3 days occurred in one patient (weeks 13 and 14), while, in one patient, the last administration of cetuximab (week 14) was not given due to the patient's request. These modifications did not represent a DLT. An interruption of radiotherapy occurred in two patients but was not considered as a DLT. In one patient, the doses of both 5-FU and cisplatin were reduced by $75 \%$ during course 3 due to lab abnormality/adverse events and not given during course 4 due to the patient's request. In another patient, the 5-FU dose was reduced by $25 \%$ and cisplatin was not given during course 4 due to lab abnormality/adverse events. None of these delays and dose reductions was due to a DLT. In the three patients treated at dose level 1, thirteen grade 3 adverse events (worst case per patient) occurred (Table III) and four serious adverse events (SAEs) were observed. One SAE (dysphagia) occurred during the period of radiotherapy (day 15 since the start of treatment) but was not related to treatment. Three serious SAEs, namely renal toxicity, pneumonia and herpes zoster infection, occurred following radiotherapy on days 75, 84 and 98 since the start of treatment, respectively, and were considered definitely related, not related and not likely related to treatment, respectively. None of these events represented a DLT.

In consequence, the next three patients were treated at dose level 2 (Table II). In all of these patients, a delay of the cetuximab administration of more than 3 days was noted, either due to lab abnormality/adverse events, patient's request or organizational reasons. The delay occurred in one patient in week 13 (for 10 days), in one patient in week 4 (for 13 days) and in one patient in weeks 7, 9 and 10 (for 7, 7 and 4 days, respectively). Furthermore, in one patient the cetuximab administration in week 3 was reduced by $20 \%$. An interruption of radiotherapy occurred in two patients but was not regarded as DLT. In one patient, the dose of cisplatin was reduced by $25 \%$ during course 2 (due to lab abnormality/adverse events), while the dose of 5 -FU was reduced by $25 \%$ during course 3 (patient's request). In the same patient, courses 2 to 4 were delayed by 14 days. As in dose level 1 , none of the delays and dose reductions was caused by a DLT. In the three patients treated at dose level 2, five grade 3 adverse events (worst case per patient) occurred (Table IV), whereas two patients experienced a SAE. One SAE (pleuritis) occurred during the period of radiotherapy (day 28 since start of treatment) but was not related to treatment. The other SAE, infection, occurred on day 84 and was considered probably related to treatment. Both events did not represent a DLT. 
Table I. Definition of dose limiting toxicities (DLTS).

- Febrile neutropenia $\left(>38.5^{\circ} \mathrm{C}\right.$ lasting longer than 24 hours, absolute neutrophil count $\left.<0.5 \times 10^{9} / 1\right)$

- Neutropenia grade 4 for more than 7 days

- Thrombopenia > grade 3

- Gastrointestinal toxicity (diarrhea) grade 3 lasting longer than 72 hours despite early antidiarrheal medication or gastrointestinal toxicity grade 4

- Stomatitis $>$ grade 3

- Vomiting grade 4

- Skin toxicity grade 4 in the irradiated region

- Hepatic toxicity $>$ grade 3

- Administered dose of chemotherapy or radiotherapy differs more than $30 \%$ from the planned dose per time interval (dose density)

- Any toxicity leading to an unplanned hospitalization

- Any life-threatening toxicity

- Any toxicity leading to the termination of chemotherapy or immunotherapy or leading to an interruption of any treatment modality of more than 2 weeks

Skin toxicity and an allergic or hypersensitivity reaction related to cetuximab were not regarded as DLTs.

Table II. Patients' characteristics.

\begin{tabular}{lcccccc}
\hline Dose level & Patient & Gender & Age (years) & Karnofsky performance score (\%) & Tumor stage & Histology \\
\hline 1 & 01 & Male & 71 & 100 & T4N2M0 & SCC \\
1 & 02 & Female & 58 & 90 & T3N1M0 & SCC \\
1 & 03 & Male & 50 & 80 & T3N1M1a & Adenocarcinoma \\
2 & 04 & Male & 58 & 100 & TxN2M0 & SCC \\
2 & 05 & Female & 70 & 80 & T4N2M0 & Adenocarcinoma \\
2 & 06 & Male & 61 & 90 & T4N1M1a & SCC \\
\hline
\end{tabular}

SCC, Squamous cell carcinoma.

At dose level 1, best response was stable disease in one patient, partial response in one patient and complete response in one patient, respectively. At dose level 2, one patient had systemic progression with locally controlled disease, one patient stable disease and one patient partial response, respectively.

\section{Discussion}

The optimal treatment of locally advanced esophageal cancer is controversial (12-15). The decisions with respect to appropriate treatment approach are often made on an individualized basis taking into account several factors, including the patient's age, general condition and comorbidities. According to a retrospective study of 148 patients, the best results for patients with locally advanced disease are achieved with neoadjuvant radio-chemotherapy plus microscopically complete (R0) resection (16). If a R0resection appears unlikely, radio-chemotherapy should be continued and given as definitive treatment, since neoadjuvant radio-chemotherapy plus incomplete ( $\mathrm{R} 1 / 2)$ resection resulted in worse outcomes than definitive radiochemotherapy alone. In this retrospective study, the 1-year survival rates were $90 \%$ after neoadjuvant radiochemotherapy (41.4-50.4 Gy) plus R0-resection, 22\% after neoadjuvant radio-chemotherapy plus $\mathrm{R} 1 / 2$-resection and $47 \%$ after definitive radio-chemotherapy (59.4-66.6 Gy), respectively (16). The 1-year rates of locoregional control were $94 \%, 19 \%$ and $52 \%$, respectively.

Patients with unresectable esophageal cancer have a significantly worse prognosis than those with resectable disease and require particular attention. After publication of the results of a randomized trial in 1992, which demonstrated that radio-chemotherapy was superior to radiotherapy alone (median survival times $=12.5$ vs. 8.9 months, $p<0.001$ ), radio-chemotherapy with 5 -FU and cisplatin became the standard regimen for definitive treatment of esophageal cancer (7). In the 1992 trial, chemotherapy included four courses of 5 -FU $\left(1,000 \mathrm{mg} / \mathrm{m}^{2} /\right.$ day on days $\left.1-4\right)$ and cisplatin (75 mg/m $\mathrm{m}^{2}$ on day 1 ). Two courses were administered concurrently with radiotherapy and two courses following radiotherapy. In order to achieve a better radio-sensitizing effect and decrease acute toxicity, $75 \mathrm{mg} / \mathrm{m}^{2}$ cisplatin given on day 1 may be replaced by $20 \mathrm{mg} / \mathrm{m}^{2}$ cisplatin on days 1 4 (16-20). However, the results of definitive radiochemotherapy for esophageal cancer are still unsatisfactory 
Table III. Adverse events (worst case per patient) in patients treated at dose level 1.

\begin{tabular}{lc}
\hline Adverse event & Number of patients \\
\hline Anemia & 1 \\
Leukopenia & 1 \\
Neutropenia & 1 \\
Nausea/vomiting & 1 \\
Esophageal stenosis & 1 \\
Hypoalbuminemia & 1 \\
Herpes zoster infection & 1 \\
Skin toxicity & 1 \\
Pneumonia & 1 \\
Night sweats & 1 \\
Weight loss & 1 \\
Performance status & 1 \\
Pain & 1 \\
\hline
\end{tabular}

Table IV. Adverse events (worst case per patient) in patients treated at dose level 2.

\begin{tabular}{lc}
\hline Adverse event & Number of patients \\
\hline Nausea & 1 \\
Infection & 1 \\
Exanthema & 1 \\
Dyspnea & 1 \\
Allergic reaction & 1 \\
\hline
\end{tabular}

and require improvement. Escalation of the radiation dose did not result in better survival rates according to the results of phase II trial (8). Improvement of the patients' prognosis may, therefore, be achieved with intensification of the systemic treatment.

Today, new neoadjuvant radio-chemotherapy regimens are under investigation. In a phase I/II trial, radiation with docetaxel and oxaliplatin in patients with advanced cancer of the esophagogastric junction appeared safe and showed efficacy with a median overall survival of 29.5 months in patients treated at the higher dose level (21). One option would be the addition of modern targeted therapies, such as EGFR antibodies, which resulted in significantly improved outcomes in patients irradiated for head-and-neck cancers $(10,11)$. In a randomized phase III trial of 424 head-and-neck cancer patients, the median survival times were 49.0 months after radiotherapy plus cetuximab and 29.3 months after radiotherapy alone $(p=0.018)(8)$. The 5-year survival rates were $46 \%$ and $36 \%$, respectively (11). For this reason, the present phase I study investigated the feasibility of the addition of a treatment regimen that included radiotherapy, 5-FU, cisplatin and the EGFR antibody cetuximab. Similar to other studies, cetuximab was well-tolerated and caused no DLT (22, 23). A grade 1 cetuximab associated acneiform rash was observed in two patients, i.e. in one patient at each dose level. According to previous studies, such skin reactions caused by cetuximab are well manageable $(10,11,24)$. In addition, a grade $\geq 2$ acneiform rash was reported to be a marker for response to treatment with cetuximab (25). The results of the present study agree with this finding taking into account the relatively unsatisfactory response and the absence of $a \geq 2$ acneiform rash. This may be the result of a low expression of EGFR and mutation of the $K-R A S$ gene of the tumors investigated in this study (26). Currently it is not clear whether addition of cetuximab to the radio-chemotherapy of esophageal cancer can improve the overall survival of these patients (27, $28)$. In the SCOPE1 trial, treatment included two courses of induction chemotherapy with cisplatin $\left(60 \mathrm{mg} / \mathrm{m}^{2}\right.$ on day 1) and capecitabine $\left(625 \mathrm{mg} / \mathrm{m}^{2}\right.$ twice daily on days 1-21) followed by radio-chemotherapy with 50 Gy of radiotherapy plus two concurrent courses of chemotherapy with or without the addition of cetuximab. In this trial, patients receiving cetuximab had a worse median survival (22.1 vs. 25.4 months, $p=0.035)$. However, the treatment programs used in the SCOPE1-trial for definitive treatment appeared not optimal. The radiation dose appeared relatively low and induction chemotherapy may have led to anemia and subsequent tumor hypoxia, which is known to impair the effect of radiotherapy (29). In contrast to the SCOPE1-trial, the preliminary results of a randomized phase II study showed a better progressionfree survival (PFS) in patients receiving cetuximab in addition to radio-chemotherapy (27). In this phase II study, radiochemotherapy included 59.4 Gy of radiotherapy plus two concurrent courses of cisplatin $\left(20 \mathrm{mg} / \mathrm{m}^{2}\right.$ on days $\left.1-4\right)$ and 5 -FU $\left(1,000 \mathrm{mg} / \mathrm{m}^{2}\right.$ on days $\left.1-4\right)$ followed by two additional courses of cisplatin $\left(20 \mathrm{mg} / \mathrm{m}^{2}\right.$ on days 1-4) and $5-\mathrm{FU}$ $\left(750 \mathrm{mg} / \mathrm{m}^{2}\right.$ on days 1-4). Median times of PFS were 15.5 months in patients receiving cetuximab versus 4.1 months in patients of the radio-chemotherapy alone group. Considering these contradictory results, it becomes obvious that additional studies are required. The main goal of the present work was to identify the maximum tolerated dose of 5-FU taking into account the occurrence of DLTs by using the traditional 3+3 design. The three patients treated at dose level 1 did not experience any DLT. Therefore, one could proceed to dose level 2. Three patients were treated at this dose level and, again, no DLT occurred. Hence, both dose levels could be considered safe and feasible.

In summary, according to the results of this phase I study, 59.4 Gy of radiotherapy supplemented by chemotherapy with $20 \mathrm{mg} / \mathrm{m}^{2}$ of cisplatin and $1,000 \mathrm{mg} / \mathrm{m}^{2}$ of 5 -FU on days 1 4 and additional weekly administration of cetuximab appeared a safe regimen. Consequently, it is used as experimental arm for a subsequent randomized phase II study (27). 


\section{Conflicts of Interest}

The present investigator-initiated trial (IIT) was funded by Merck Serono. In addition to the study grant, D.R. received speaker's honoraria and travel grants from Merck Serono.

\section{References}

1 Siegel RL, Miller KD and Jemal A: Cancer Statistics, 2017. CA Cancer J Clin 67: 7-30, 2017.

2 Ferlay J, Bray F and Pisani P: GLOBOCAN 2000: Cancer Incidence, Mortality and Prevalence Worldwide, Version 1.0. IARC Cancer Base No. 5. Lyon, France: IARC Press, 2001.

3 Lutz MP, Zalcberg JR, Ducreux M, Ajani JA, Allum W, Aust D, Bang YJ, Cascinu S, Hölscher A, Jankowski J, Jansen EP, Kisslich R, Lordick F, Mariette C, Moehler M, Oyama T, Roth A, Rueschoff J, Ruhstaller T, Seruca R, Stahl M, Sterzing F, van Cutsem E, van der Gaast A, van Lanschot J, Ychou M and Otto F; First St Gallen EORTC Gastrointestinal Cancer Conference 2012 Expert Panel: Highlights of the EORTC St. Gallen International Expert Consensus on the primary therapy of gastric, gastroesophageal and oesophageal cancer - Differential treatment strategies for subtypes of early gastroesophageal cancer. Eur J Cancer 48: 2941-2953, 2012.

4 Moehler M, Baltin CT, Ebert M, Fischbach W, Gockel I, Grenacher L, Hölscher AH, Lordick F, Malfertheiner P, Messmann H, Meyer HJ, Palmqvist A, Röcken C, Schuhmacher C, Stahl M, Stuschke M, Vieth M, Wittekind C, Wagner D and Mönig SP: International comparison of the German evidencebased S3-guidelines on the diagnosis and multimodal treatment of early and locally advanced gastric cancer including adenocarcinoma of the lower esophagus. Gastric Cancer 18: 550-563, 2015.

5 Le Bras GF, Farooq MH, Falk GW and Andl CD: Esophageal cancer: The latest on chemoprevention and state of the art therapies. Pharmacol Res 113: 236-244, 2016.

6 Bedenne L, Michel P, Bouché, O Milan C, Mariette C, Conroy T, Pezet D, Roullet B, Seitz JF, Herr JP, Paillot B, Arveux P, Bonnetain $\mathrm{F}$ and Binquet $\mathrm{C}$ : Chemoradiation followed by surgery compared with chemoradiation alone in squamous cancer of the esophagus: FFCD 9102. J Clin Oncol 25: 11601168, 2007.

7 Herskovic A, Martz K, Al-Sarraf M, Leichman L, Brindle J, Vaitkevicius V, Cooper J, Byhardt R, Davis L and Emami B: Combined chemotherapy and radiotherapy compared with radiotherapy alone in patients with cancer of the esophagus. $\mathrm{N}$ Engl J Med 326: 1593-1598, 1992.

8 Minsky BD, Pajak TF, Ginsberg RJ, Pisansky TM, Martenson J, Komaki R, Okawara G, Rosenthal SA and Kelsen DP: INT 0123 (Radiation Therapy Oncology Group 94-05) Phase III Trial of combined-modality therapy for esophageal cancer: High-dose versus standard radiation therapy. J Clin Oncol 20: 1167-1174, 2002.

9 Cooper JS, Guo MD, Herskovic A Macdonald JS, Martenson JA Jr, Al-Sarraf M, Byhardt R, Russell AH, Beitler JJ, Spencer S, Asbell SO, Graham MV and Leichman LL: Chemoradiotherapy of locally advanced esophageal cancer - Long-term follow-up of a prospective randomized trial (RTOG 85-01). JAMA 281: 1623-1627, 1999
10 Bonner JA, Harari PM, Giralt J, Azarnia N, Shin DM, Cohen RB, Jones CU, Sur R, Raben D, Jassem J, Ove R, Kies MS, Baselga J, Youssoufian H, Amellal N, Rowinsky EK and Ang KK: Radiotherapy plus cetuximab for squamous-cell carcinoma of the head and neck. NEJM 354: 567-578, 2006.

11 Bonner JA, Harari PM, Giralt J, Cohen RB, Jones CU, Sur RK, Raben D, Baselga J, Spencer SA, Zhu J, Youssoufian H, Rowinsky EK and Ang KK: Radiotherapy plus cetuximab for locoregionally advanced head and neck cancer: 5-year survival data from a phase 3 randomised trial, and relation between cetuximab-induced rash and survival. Lancet Oncol 11: 21-28, 2010.

12 Haefner MF, Lang K, Krug D, Koerber SA, Uhlmann L, Kieser M, Debus $\mathrm{J}$ and Sterzing F: Prognostic factors, patterns of recurrence and toxicity for patients with esophageal cancer undergoing definitive radiotherapy or chemo-radiotherapy. J Radiat Res 56: 742-749, 2015.

13 Tozzi A, Iftode C, Cozzi L, Ascolese AM, Battista S, Cavina R, Clerici E, Comito T, D'Agostino GR, De Rose F, Franzese C, Garassino I, Romario UF, Navarria P, Rosati R, Spaggiari P, Tomatis S and Scorsetti M: Neoadjuvant chemoradiotherapy with volumetric-modulated arc therapy for medium-distal oesophageal and gastro-oesophageal junction carcinoma. Anticancer Res 35: 4109-4116, 2015.

14 Hosoda K, Yamashita K, Katada N, Moriya H, Mieno H, Sakuramoto S, Kikuchi $\mathrm{S}$ and Watanabe M: Impact of lower mediastinal lymphadenectomy for the treatment of esophagogastric junction carcinoma. Anticancer Res 35: 445456, 2015.

15 Ojima T, Nakamori M, Nakamura M, Katsuda M, Hayata K, Kato T, Kitadani J, Tabata H, Takeuchi A, Iwahashi $\mathrm{M}$ and Yamaue H: Neoadjuvant chemotherapy with divided-dose docetaxel, cisplatin and fluorouracil for patients with squamous cell carcinoma of the esophagus. Anticancer Res 36: 829-834, 2016.

16 Rades D, Schulte R, Yekebas EF, Homann N, Schild SE and Dunst J: Radio-(chemo)therapy plus resection versus radio(chemo)therapy alone for the treatment of stage III esophageal cancer. Strahlenther Onkol 183: 10-16, 2007.

17 Tribius S, Kronemann S, Kilic Y, Schroeder U, Hakim S, Schild SE and Rades D: Radiochemotherapy including cisplatin alone versus cisplatin +5 -fluorouracil for locally advanced unresectable stage IV squamous cell carcinoma of the head and neck. Strahlenther Onkol 185: 675-681, 2009.

18 Rades D, Kronemann S, Meyners T, Bohlen G, Tribius S, Kazic N, Schroeder U, Hakim SG, Schild SE and Dunst J: Comparison of four cisplatin-based radiochemotherapy regimens for nonmetastatic stage III/IV squamous cell carcinoma of the head and neck. Int J Radiat Oncol Biol Phys 80: 1037-1044, 2011.

19 Fietkau R, Lautenschläger C, Sauer R, Dunst J, Becker A, Baumann M, Wendt K, Gruschow K, Hess C, Budach V and Iro $\mathrm{H}$ : Postoperative concurrent radiochemotherapy versus radiotherapy in high-risk SCCA of the head and neck: Results of the German phase III trial ARO 96-3. J Clin Oncol 24(Suppl): 5507, 2006.

20 Semrau S, Haderlein M, Schmidt D, Lell M, Wolf W, Waldfahrer F, Uder M, Iro H, Kuwert $\mathrm{T}$ and Fietkau R: Single-cycle induction chemotherapy followed by chemoradiotherapy or surgery in patients with head and neck cancer: What are the best predictors of remission and prognosis? Cancer 121: 1214-1222, 2015. 
21 Moehler M, Gockel I, Roessler HP, Arnold D, Trarbach T, Thomaidis T, Klautke G, Rödel C, Brenner B, Lang H, Galle PR, Schimanski CC and Schmidberger H: Prospective, open, multicentre phase I/II trial to assess safety and efficacy of neoadjuvant radiochemotherapy with docetaxel and oxaliplatin in patients with adenocarcinoma of the oesophagogastric junction. BMC Cancer 13: 75, 2013.

22 Meng X, Wang J, Sun X, Wang L, Ye M, Feng P, Zhu G, Lu Y, Han C, Zhu S, Liao Z and Yu J: Cetuximab in combination with chemoradiotherapy in Chinese patients with non-resectable, locally advanced esophageal squamous cell carcinoma: A prospective, multicenter phase II trial. Radiother Oncol 109: 275-280, 2013.

23 Chen Y, Wu X, Bu S, He C, Wang W, Liu J, Guo W, Tan B, Wang $Y$ and Wang J: Promising outcomes of definitive chemoradiation and cetuximab for patients with esophageal squamous cell carcinoma. Cancer Sci 103: 1979-1984, 2012.

24 Schimanski CC, Staib F, Göhler T, Hebart H, Heike M, Neise M, Rudi J, Geer T, Dingeldein G, Lang C, Ehscheidt P, Flohr T, Josten KM, Karthaus M, Schmittel A, Wierecky J, Boller E, Indorf M, Wörns MA, Galle PR and Moehler M: Dermatux: phase IV trial of Cetuximab plus FOLFIRI in first-line metastatic colorectal cancer receiving a pre-defined skin care. J Cancer Res Clin Oncol, in press, 2017. doi: 10.1007/s00432017-2344-3. [Epub ahead of print]

25 Van Cutsem E, Tejpar S, Vanbeckevoort D, Peeters M, Humblet Y, Gelderblom H, Vermorken JB, Viret F, Glimelius B, Gallerani E, Hendlisz A, Cats A, Moehler M, Sagaert X, Vlassak S, Schlichting $M$ and Ciardiello F: Intrapatient cetuximab dose escalation in metastatic colorectal cancer according to the grade of early skin reactions: the randomized EVEREST study. J Clin Oncol 30: 2861-2868, 2012.
26 Bokemeyer C, Van Cutsem E, Rougier P, Ciardiello F, Heeger S, Schlichting M, Celik I and Köhne CH: Addition of cetuximab to chemotherapy as first-line treatment for KRAS wild-type metastatic colorectal cancer: Pooled analysis of the CRYSTAL and OPUS randomised clinical trials. Eur J Cancer 48: 14661475, 2012.

27 Rades D, Moehler MH, Debus J, Belka C, Homann N, Petersen C, Ridwelski K, Reyes R and Kranich AL: LEOPARD-II: A randomized phase II study of radiochemotherapy (RCT) with $5 \mathrm{FU}$ and cisplatin plus/minus cetuximab (Cet) in unresectable locally advanced esophageal cancer (LAEC). J Clin Oncol 32(suppl): abstr 4081, 2014.

28 Crosby T, Hurt CN, Falk S, Gollins S, Mukherjee S, Staffurth J, Ray R, Bashir N, Bridgewater JA, Geh JI, Cunningham D, Blazeby J, Roy R, Maughan $\mathrm{T}$ and Griffiths $\mathrm{G}$ : Chemoradiotherapy with or without cetuximab in patients with oesophageal cancer (SCOPE1): A multicentre, phase 2/3 randomised trial. Lancet Oncol 14: 627-637, 2013.

29 Vaupel P, Mayer A and Höckel M: Impact of hemoglobin levels on tumor oxygenation: The higher, the better? Strahlenther Onkol 182: 63-71, 2006. 